\title{
Clinical Implications of Internet Infidelity: Where Facebook Fits In
}

Jaclyn D. Cravens

Alliant International University - San Diego

Jason B. Whiting PhD

Brigham Young University, jason.whiting@byu.edu

Follow this and additional works at: https://scholarsarchive.byu.edu/facpub

Part of the Marriage and Family Therapy and Counseling Commons, and the Social Media Commons

\section{Original Publication Citation}

Cravens, J. D., \& Whiting, J. B. (2014). Clinical implications of internet infidelity: Where Facebook fits in. The American Journal of Family Therapy, 1-15, DOI: 10.1080/81926187.2013.874211

\section{BYU ScholarsArchive Citation}

Cravens, Jaclyn D. and Whiting, Jason B. PhD, "Clinical Implications of Internet Infidelity: Where Facebook Fits In" (2014). Faculty Publications. 2165.

https://scholarsarchive.byu.edu/facpub/2165

This Peer-Reviewed Article is brought to you for free and open access by BYU ScholarsArchive. It has been accepted for inclusion in Faculty Publications by an authorized administrator of BYU ScholarsArchive. For more information, please contact ellen_amatangelo@byu.edu. 
This article was downloaded by: [Jaclyn Cravens]

On: 02 June 2014, At: 13:08

Publisher: Routledge

Informa Ltd Registered in England and Wales Registered Number: 1072954 Registered office: Mortimer House, 37-41 Mortimer Street, London W1T 3J H, UK

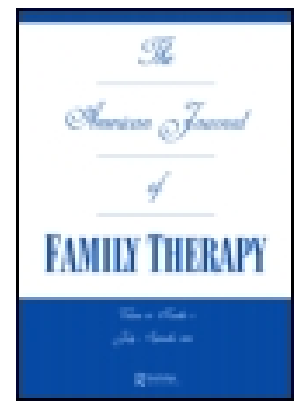

\title{
The American J ournal of Family Therapy
}

Publication details, including instructions for authors and subscription information:

http:// www. tandfonline.com/loi/ uaft20

\section{Clinical Implications of Internet Infidelity: Where Facebook Fits In}

\author{
J aclyn D. Cravens ${ }^{a} \&$ J ason B. Whiting ${ }^{b}$ \\ a Alliant International University, San Diego, California, USA \\ b Texas Tech University, Lubbock, Texas, USA \\ Published online: 28 May 2014.
}

To cite this article: J aclyn D. Cravens \& J ason B. Whiting (2014): Clinical Implications of Internet Infidelity: Where Facebook Fits In, The American J ournal of Family Therapy, DOI: 10.1080/01926187.2013.874211

To link to this article: http:// dx.doi.org/ 10.1080/01926187.2013.874211

\section{PLEASE SCROLL DOWN FOR ARTICLE}

Taylor \& Francis makes every effort to ensure the accuracy of all the information (the "Content") contained in the publications on our platform. However, Taylor \& Francis, our agents, and our licensors make no representations or warranties whatsoever as to the accuracy, completeness, or suitability for any purpose of the Content. Any opinions and views expressed in this publication are the opinions and views of the authors, and are not the views of or endorsed by Taylor \& Francis. The accuracy of the Content should not be relied upon and should be independently verified with primary sources of information. Taylor and Francis shall not be liable for any losses, actions, claims, proceedings, demands, costs, expenses, damages, and other liabilities whatsoever or howsoever caused arising directly or indirectly in connection with, in relation to or arising out of the use of the Content.

This article may be used for research, teaching, and private study purposes. Any substantial or systematic reproduction, redistribution, reselling, loan, sub-licensing, systematic supply, or distribution in any form to anyone is expressly forbidden. Terms \& Conditions of access and use can be found at http://www.tandfonline.com/page/termsand-conditions 


\title{
Clinical Implications of Internet Infidelity: Where Facebook Fits In
}

\author{
JACLYN D. CRAVENS \\ Alliant International University, San Diego, California, USA \\ JASON B. WHITING \\ Texas Tech University, Lubbock, Texas, USA
}

\begin{abstract}
The Internet can enbance existing relationships or facilitate the development of new relationships, including illicit ones. Increased research in this area has predominately been on online sexual addiction and pornography, with few about social networking sites. Facebook, a popular social networking site boasting 1.15 billion active users. This article reviews existing literature on Internet infidelity, comparing online activities and Facebook-specific behaviors. Five areas related to Internet infidelity will be explored, such as definitions and the impact on relationships. Although several similarities exist between general Internet and Facebook-specific infidelity, unique differences exist. Implications for future research and clinical practice are presented.
\end{abstract}

"I created my own account and sent him a friend request. He denied it. I asked him to change his relationship status to married or at least that he was in a relationship. He refused. I became obsessed with reading the comments."

"I was with my wife for 15 years. She decided to join Facebook in March 2012. She wanted to contact old friends from school and work to find out about what they have been up to... She knew him when she was 12 years old, met him 20 years later for one night and now says she loves him. Its madness... There is no sign of remorse or forgiveness. . Facebook not only changes peoples' lives it can ruin it."

—Anonymous postings, Facebookcheating.com

Address correspondence to Jaclyn D. Cravens, Ph.D., Assistant Professor, California School of Professional Psychology, Alliant International University, 10455 Pomerado Road, DH-204, San Diego, CA 92131. E-mail: jcravens@alliant.edu 
Facebook is a website that allows users to create a profile containing self-description, personal likes, hobbies and affiliations. It allows users to interact through viewing profiles, writing posts, sharing pictures, sending private messages, and online chatting. Launched in 2004, Facebook is one of the most popular social networking sites (SNS) in the world. With one billion active users about one in every seven people on the planet actively use this site (Smith, Segall, \& Cowley, 2012). Benefits such as staying updated and interacting with users around the world have not come without consequences, as highlighted by the quotes at the start of the paper. For example, The American Association of Matrimonial Lawyers recently released information on the growing number of divorce cases that cite Facebook as a contributing factor in the dissolution of marriage (Lumpkin, 2012). In 2011, over one third of divorce cases contained the word Facebook (Lumpkin, 2012). Also, an entire website has been devoted to the phenomenon of Facebook cheating. Facebookcheating.com allows users to anonymously post stories about their experiences with Facebook infidelity and to receive support from other users.

Despite the rise of Facebook related relationship problems, including infidelity, few empirical studies are devoted to understanding this phenomenon. A large amount of literature exists on the topic of Internet sexuality (i.e., locating information about sexual issues, pornography, purchasing sex related merchandise), with some literature existing on Internet infidelity in general; however, SNS infidelity behaviors receive less attention. The purpose of this article is to review the existing literature on Internet infidelity focusing on what similarities and differences might exist between other online infidelity behaviors and Facebook-specific infidelity behaviors. Articles for review were located using the following combination of the keywords: Internet, cyber, online, social networking, and Facebook with infidelity, affair, and cheating. This article will compare Internet and Facebook-specific infidelity in the following areas:

1. Defining infidelity;

2. Beliefs about Internet infidelity;

3. Motivational factors for Internet infidelity;

4. The impact of Internet infidelity on relationships;

5. Online boundaries and rules.

\section{DEFINING OFFLINE AND ONLINE INFIDELITY}

One of the main challenges of studying online infidelity is defining what constitutes infidelity. This is not surprising since offline infidelity is such an elusive term. Early definitions of offline infidelity narrowly focused only on one partner engaging in sexual intercourse with someone outside the relationship 
(Johnson, 1972; Thompson, 1983). More recent studies on offline infidelity have expanded this definition. Glass and Wright (1992) categorized infidelity as falling into three different groups of behavior: sexual, emotional, or a combination of the two. In addition to Glass and Wright's (1992) three categories of infidelity, Wilson, Mattingly, Clark, Weidler, and Bequette (2011) determined that infidelity can be separated into three types: ambiguous, which includes going someplace, buying/receiving gifts, dancing, hugging, talking on the phone/internet, and eating/drinking; deceptive, which consists of lying and withholding information; and explicit, which includes heavy petting/fondling, dating, intercourse, and oral sex. Explicit behaviors directly related to sexual infidelity were identified as the strongest indicators of cheating, while ambiguous and deceptive behaviors fell more in line with emotional infidelity.

Several studies have revealed that participants have a diverse opinion of what behaviors constitute infidelity. Roscoe, Cavanaugh, and Kennedy (1988) found that undergraduate university students defined three different behaviors being indicative of offline infidelity: dating or spending time with a different partner; having sexual intercourse with someone else; and engaging in other sexual interactions with someone else such as kissing, flirting or petting. Participants in a study by Yarab, Sensibaugh, and Allgeier (1998) defined infidelity as: sexual intercourse, passionately kissing, sexual fantasies, non-sexual fantasies about falling in love, sexual attraction, romantic attraction, flirting, and dyadic behaviors such as studying, having lunch, or going to a movie with someone other than your partner.

Definitions of online infidelity are equally as assorted. Cooper and Griffin-Shelley (2002) state that online infidelity is any activity that "involves sexuality for purposes of recreation entertainment, exploration, support, education, commerce, efforts to attain or secure sexual or romantic partners, and so on" (p. 3). Hertlein and Piercy (2008) define Internet infidelity "as a romantic or sexual contact facilitated by Internet use that is seen by at least one partner as an unacceptable breach of their marital contract of faithfulness" (p. 484). A critical review of the literature on Internet infidelity revealed that the one element "that remains stable across these definitions is secrecy" (Hertlein \& Piercy, 2006, p. 367). Secrecy occurs in online infidelity through a variety of methods: closing out of chat windows when a partner walks in the room, deleting the computer history, erasing online interactions, or pretending to be working on something else when engaging in Internet infidelity behaviors (Hertlein \& Piercy, 2006; Schneider, 2000).

\section{DEFINING FACEBOOK INFIDELITY}

Just like with other types of infidelity, users of Facebook differ in what they view to be cheating. Cravens, Leckie, and Whiting (2013) found that 
participants who had experienced Facebook infidelity struggled to decide whether a behavior was inappropriate or not. Additionally, these participants reported a range of different Facebook-specific behaviors that sometimes were inappropriate: friending an ex-partner or ex-spouse, friending attractive members, sending private messages to the opposite sex, commenting on attractive users pictures, not having up the correct relationship status on their profile, and not allowing their partner to be their friend on Facebook. Participants also mentioned that their partners did not always agree with what behaviors constituted infidelity or inappropriate behaviors, which added to the difficulty of deciding whether it was infidelity.

Secrecy is also an issue for Facebook infidelity. Users are able to have their own accounts with passwords that prevent their partners from knowing what they are doing. The ability to send other users private messages and to chat with people while logged into their account makes it easy to engage in inappropriate behaviors even while their partner is in the same room. Additionally, Facebook allows for the creation of "fake" accounts or multiple profiles. If a partner has an account that is kept secret, this could precede infidelity behaviors.

In sum, Facebook infidelity is similar to other forms of Internet infidelity in that it is difficult to define and individuals hold differing opinions about what Facebook behaviors would count as infidelity. What is unique about Facebook infidelity is the level of interaction that Facebook affords its users. Facebook users can view profiles, browse through picture, chat in live time, send private messages, and invite other users to play online games, providing Facebook users with more ways to interact and connect with users than chat rooms or other Internet mediums. Also, some partners may have a stronger reaction to behaviors that involve Facebook friends, since these friends can be interacted with both online and offline. For example, a partner may be more distraught about a social networking interaction with an offline friend than one with a chat room user on the other side of the globe since the perceived infidelity may continue offline. This hypothesis is supported by findings in Yarab, Sensibaugh, and Allgeier (1998) who found that participants had stronger reactions to interactions that were more likely to be continued offline (e.g., meeting a porn-star offline is less likely than meeting someone met in a chat room).

\section{INTERNET INFIDELITY: IS IT CHEATING?}

Internet researchers have questioned to what extent online interactions could develop into meaningful relationships since there are few nonverbal interactions (Kraut et al., 1998). Researchers and clinicians have since found that individuals can successfully establish or maintain relationships including friendships and romantic partnerships online. With the establishment of 
relationships online came relationship betrayal and infidelity (Henline \& Lamke, 2003; Henline, Lamke, \& Howard, 2007; Whitty, 2003, 2005).

Henline and Lamke (2003) found that participants considered online infidelity to not only consist of sexual components but emotional as well. Similarly, Whitty (2003) asked participants to rank 15 pre-determined behaviors on a scale from no infidelity to extreme infidelity. The study resulted in the creation of three separate categories of infidelity: sexual infidelity, emotional infidelity, and pornography use. Building upon this, Whitty (2005) explored the impact of online infidelity on offline relationships, finding that participants generally identified the online behavior as cheating. Participants reported impacts similar to those reported on offline infidelity (see Kitzinger \& Powell, 1995), such as guilt over the affair, less time spent with the partner, shame, loss of trust, and ending the relationship.

In 2007, Henline, Lamke, and Howard compared perceptions of online and traditional infidelity using a sample of individuals in a committed partnership. Henline and colleagues (2007) asked participants "What online behaviors or activities would you consider to be "unfaithful' to a dating partner if the couple is in an exclusive dating relationship?" Results of the study found that there were four activities that were rated most unfaithful: online sex, emotional involvement with an online contact, online dating, and other online sexual interactions. Additionally, $60-82 \%$ of the participants identified emotional online behaviors to be more damaging than online sexual behaviors.

\section{FACEBOOK: DOES IT FACILITATE AFFAIRS?}

With the growing number of divorces citing Facebook as a contributing factor, and websites that highlight stories of Facebook cheating, there is little doubt that Facebook has the ability to facilitate infidelity behaviors and impact offline relationships. Cravens and Whiting (2014) replicated two studies that asked participants to interpret whether or not a specific behavior in a cue story about offline (Kitzinger \& Powell, 1995) and online (Whitty, 2005) behaviors were considered cheating. In this study, participants responded to a cue story specifically identifying Facebook as the online medium facilitating the behavior. Slightly over half of the participants (51.4\%) identified the partner's behavior as infidelity. Additionally, the participants identified similar impacts to the offline relationships as have previous studies.

One unique finding of this study is related to the specific functions of Facebook. For example, participants discussed embarrassment and shame associated with other online users being aware of the infidelity behaviors their partner was committing (e.g., posts made on their wall, third parties commenting on pictures). Also, despite participating partners being "caught in the act" some played the role of victim stating that their privacy had been 
invaded since their partner had been on their private account. Lastly, participants discussed aspects of retaliation that were Facebook-specific, such as blocking the partner, de-friending them, contacting the third party using Facebook, stalking or checking out the third party by viewing their Facebook profile, or writing status updates that discussed the issues in their relationship.

\section{MOTIVATIONAL FACTORS}

Several models have been created to explain how Internet infidelity is different from offline infidelity (Cooper, 1998), why it is an addicting medium for establishing relationships (Young, 1998), how it facilitates the development of relationships (Leiblum \& Döring, 2002) or how it relates to intimacy problems (Hertlein \& Stevenson, 2010). One of the first models to be created was Cooper's (1998) triple "A" engine that identified three factors, accessibility, affordability, and anonymity that makes online infidelity different from offline. This model was adapted, adding a fourth "A," approximation. Approximation covers the area of experimentation that the Internet affords users (e.g., experimenting with sexual fantasies, or trying out new behaviors one may not feel comfortable with offline) (Ross et al., 2005). Both Young (1998) and Leiblum and Döring (2002) created models that mirror Cooper's (1998) three-factor model. Young (1998) developed the ACE model (Anonymity, Convenience, Escape), which was created as an attempt to explain why Internet behaviors become addicting. Leiblum and Döring (2002) created the triple C engine, which focuses on the interactive components of the Internet: communication, collaboration, and communities. These models highlight the importance of relational and interactive components that affect Internet infidelity.

Building off of existing literature, Hertlein and Stevenson (2010) conducted an in-depth review of published empirical studies that examined contributing factors of Internet related intimacy problems. They identified five "As" (anonymity, accessibility, affordability, approximation, acceptability) cited within published literature, with an additional two "As" (ambiguity, accommodation) they believe are represented in previous studies. They point out that if a partner feels confined or restricted in their relationship, the Internet provides them with a forum to pursue their ideal vision of self.

\section{MOTIVATIONAL FACTORS FOR FACEBOOK INFIDELITY}

No studies to date have been conducted to test whether the existing motivational factor models for Internet infidelity would be valid models for Facebook infidelity. However, it seems likely that Cooper's (1998) triple "A" engine or the more comprehensive model by Hertlein and Stevenson (2010) 
could be applied to Facebook infidelity. For example, affordability and accessibility fit in the sense that Facebook and other SNS are free for their users and there is no stigma associated with accessing this website in public places. There is also ambiguity in some Facebook behaviors, such as knowing when interactive behaviors cross the line of being unacceptable. The anonymity "A" is interesting to consider, because in some ways Facebook allows its users to engage in secretive behavior (i.e., private messaging, chatting with other users if their partner was not around to witness); however, it is not anonymous activity in the sense that who you are, is for the most part known by other users. Most Facebook users create profiles that accurately portray who they are, revealing their name, work or school affiliations, email address, their city or state, and pictures of themselves. Future research could empirically validate the 7 "As" model with those individuals who have used Facebook to engage in infidelity behaviors.

\section{IMPACT OF INTERNET INFIDELITY}

Most empirical studies on the impact of Internet infidelity on the primary relationship have examined the role of pornography or Internet sexual compulsivity, with few looking at other forms of Internet infidelity (Bridges, Bergner, \& Hesson-McInnis, 2003; King, 1999; Schneider, 2000; Zitzman \& Butler, 2005). Although pornography and Internet sexual compulsivity may not be forms of infidelity that include interacting with another person online, study participants who were the partners of heavy pornography users stated that they overwhelmingly viewed their partners' activity as an act of infidelity because it reduced the exclusivity of their relationship (Bergner \& Bridges, 2002). For this reason, studies that examined pornography, Internet sexual compulsivity, and Internet infidelity will all be reviewed in this section.

One of the first researchers to examine the impact of Internet behaviors on the primary relationship was King (1999), who looked at how the wives of Clergy members who engaged in compulsive sexual behaviors were impacted by their husbands' online behaviors. Eighty-two percent of the women in the study stated that they interpreted their husband's behavior as a betrayal and reported loss of trust in the relationship as a result. Additional impacts were the loss of relationships, debt, and loss of identity within their church community.

Schneider (2000), sought to examine the role cybersex has in relationships, becoming the first empirical study that looked at the impact of Internet infidelity. Partners reported feeling hurt, betrayal, rejection, abandonment, devastation, loneliness, shame, isolation, humiliation, jealousy, and anger as well as loss of self-esteem. Participants noted a change in the relational dynamics, with $68 \%$ of the respondents stating that one or both partners had 
lost interest in relational sex. Close to one third of the participants (22.3\%) in this study reported that they had either separated or divorced due to the cybersex addiction of their partner.

The remainder of empirical studies that examine the impact of Internet behaviors on the relationship focused on pornography. Bergner, Bridges, and Hesson-McInnis (2003) found that partners of pornography viewers interpreted the behavior as a direct threat to their relationship, with participants reporting feeling loss, betrayal, devastation, anger, and mistrust. Zitzman and Butler (2005) found similar results, with the primary issue reported by participants as the need to regain trust in the relationship. Bergner and colleagues (2003) found similar experiences as those reported by the participants in the Schneider (2000) study; however, it is important to recognize that although damaging and often interpreted as being a form of infidelity, these behaviors may not have the same impact as an actual online affair with another person. Researchers have yet to examine how pornography and compulsive online sexual behaviors compare to Internet infidelity behaviors that require the emergence of a third person into the relationship.

\section{THE IMPACT OF FACEBOOK INFIDELITY}

An analysis of the postings on the website Facebookcheating.com suggests that these partners are impacted in similar ways as other types of infidelity (Cravens et al., 2013). Common emotional reactions to Facebook infidelity were: hurt, loss of trust, shock, jealousy, embarrassment, and anger. Additionally, partners struggled with the decision to stay or not stay with their partner which is also similar to offline infidelity (Schneider, 2000). Cravens and Whiting (2014) also found that in response to a hypothetical scenario about Facebook infidelity, 65\% of the participants wrote that the relationship ended. Other negative impacts included loss of trust, fighting or arguing, retaliation, and negative emotions.

One difference with Facebook infidelity could be the number of people who know about the behavior due to the popularity of Facebook for interacting with friends. If a partner is caught cheating on a chat room, those who become aware of it may be limited to friends or family who are told about the behavior. With Facebook, if the behaviors are displayed on one's wall or in posted pictures, the infidelity may be suspected or known by the Facebook user's entire online network, which could lead to greater levels of embarrassment or anger.

\section{ONLINE RULES AND BOUNDARIES}

Several of the issues with Internet infidelity relate to rules and boundaries. Individuals within a relationship have a wide variation in the behaviors they 
consider to be inappropriate in their relationship, making Internet infidelity difficult to define. Daines (2006) states that on one end of the spectrum a partner may believe viewing pornography to be sufficient enough betrayal to end the relationship; whereas, on the opposite end of the spectrum you might find a couple that is in "acceptance or even encouragement of sexual contact or emotional closeness with others that may not generally be tolerated" (p. 48).

Of the limited studies that do exist on this topic, one study looks at the couple unit. Helsper and Whitty (2010) were interested in learning whether married couples share similarities in online netiquette, or the rules and assumptions about what constitutes appropriate online behaviors. 992 couples were asked to rate 10 online activities as an act that would either make them unhappy, not care, or happy if their partner was to engage in the behavior. The results found that couples had the strongest agreement on infidelity behaviors (i.e., falling in love with someone else online and engaging in cybersex), whereas, they had the most disagreement about other problematic behaviors (e.g., online gaming, gambling, and shopping).

\section{FACEBOOK RULES AND BOUNDARIES}

Norton (2011) examined how relationship satisfaction, trust, and a history of infidelity influenced couples' boundaries and rules of SNS. One finding of Norton's study is that the five boundary items were best fit into two broader latent constructs: openness (sharing passwords, access to account) and fidelity (emotional fidelity same online as offline). Additionally, trust but not relationship satisfaction was significantly related to the use of Internet boundaries. An interesting finding was that participants reported having higher levels of trust in their relationship when they shared passwords or had access to their partner's account. Although differences in design exist between studies, this finding contrasts with the results of a study that found the majority of couples felt that monitoring a partner's Facebook account is a violation of the relationship, carrying negative consequences for the relationship (Cravens, 2013).

A more recent study explored whether couples communicate about SNS rules and boundaries, how these rules were established, and how they were monitored (Cravens, 2013). This study found that couples rarely establish rules or boundaries for Facebook and that the rules that were held were implicit and assumed to be shared. Further, couples would only communicate about Facebook issues once a problem occurred, but these conversations did not result in the development of rules for future behavior. Finally, similar to Danies (2006) study on pornography, partners within a relationship had variation in what they each viewed to be problematic or nonproblematic. This study highlights that the creation of explicit rules and boundaries rarely occur in intimate 
partner relationships, despite couples reporting problems with Facebook behaviors.

\section{DISCUSSION AND IMPLICATIONS}

Almost fifteen years have passed since researchers and clinicians started taking notice of the role the Internet was having on offline lives. This paper discusses the similarities and differences that exist between Facebook infidelity and other forms of online infidelity. The following similarities were noted: difficulty in defining both Facebook and online infidelity, viewing online and SNS behaviors as infidelity, similar impacts on the offline relationship, and disagreement about rules related to specific behaviors. A unique finding related to Facebook infidelity is the possibility of greater perceived threat of Facebook interactions due to the likelihood of the relationship occurring offline as well as online. Also initial studies found a heightened reaction to SNS accounts being accessed by one's partner, with this behavior being interpreted as a major violation of privacy. The remainder of the paper shall discuss clinical implications and areas of future research that could be conducted to fill the existing gaps.

\section{CLINICAL IMPLICATIONS}

Clinicians working with couples who have experienced Internet infidelity, specifically Facebook infidelity, will need to focus on several areas during therapy: assessment, boundary and rule setting, and processing emotions related to the infidelity. Although these are typical therapeutic tasks, they will be discussed in relation to working with Facebook infidelity.

Assessment of Facebook infidelity should focus on several factors: exploring the involved parties, how each partner views the behavior, and the motivational factors that exist. Jones and Hertlein (2012) identify four areas that can be assessed when working with online infidelity behaviors to distinguish whether it is Internet infidelity or a compulsive behavior. The first two areas of assessment-involved parties and view of the problem-specifically apply to understanding the depth and severity of the Facebook infidelity. With the involved parties, therapists should explore the location of the third party (i.e., where does the third party live in relation to the couple?), whether or not there is an additional offline relationship (i.e., is the online relationship limited to one partner or are there multiple relationships?), and what previous relationship the partner might have had with the third party (i.e., did they meet on Facebook? Did they grow up together? Is it a past romantic partner?). Gathering information about the third party is one way to assess the severity of the betrayal. Another way to 
assess for severity is exploring both partners' view of the problem. Based on the wide range of definitions of both online and offline infidelity, therapists should ask each couple they work with what behaviors constitute infidelity and whether or not both partners agree on these. It is possible that only the non-participating partner identified the behavior as infidelity, with the participating partner minimizing the behavior as nothing more than playing around online.

There currently exists a plethora of motivational factor models for Internet infidelity. Although these models are not yet validated for Facebook infidelity, clinicians could refer to Cooper (1998) Triple "A" engine or Hertlein and Stevenson (2010) 7 "As" model as an additional means to assess the behavior. The 7 "As" model is especially helpful in terms of assessing with a relational frame of reference. For example, accommodation and approximation are both motivational factors that are influenced by the primary relationship. If a partner is feeling restrained or constricted in their offline relationship (accommodation) or they either are unable to fulfill some of their fantasies or are afraid to communicate these desires to their partner (approximation), the participating partner may initiate the Facebook affair to meet these needs. The therapist may ask partners questions such as "How would you describe the state of your relationship at the time you initiated the online relationship?" or "Can you identify ways in which your online relationship offered you something different from your offline relationship? Have you ever talked with your partner about these desires?" Therapists can utilize these motivational models to explore the underlying individual and relational factors that may have influenced the decision to cheat. Caution should be advised to not use these factors to excuse the partner or blame the non-participating partner.

Another clinical issue will be defining what Facebook behaviors are considered infidelity. Due to the wide range of findings on this issue, therapists will have to ask each partner how they determine what behaviors constitute infidelity, and, when partners do not agree on their definitions, help the couple negotiate these differences.

Once the therapist and couple have defined the behaviors they deem to be inappropriate, they can focus on communicating rules and boundaries for their SNS use. Therapists should also have couples discuss how these rules and boundaries will be enforced. Will they share passwords to their accounts? Do they allow one another time to be on their personal accounts? Norton (2011) and Cravens (2013) found conflicting results about how monitoring behaviors impact relationships. Therapists should help couples discuss the possible benefits and consequences of sharing passwords, allowing the couple to ultimately decide what will work best for their relationship.

The final clinical issue that should be focused on when working with Facebook infidelity deals with processing the varied emotions related to the impact of the behavior on the non-participating partner. Therapists should 
assess for each partners' view on whether Facebook behaviors are crossing a relational boundary. If one partner sees Facebook behaviors as cheating, but the other downplays them, it is possible that the non-participating partner may not feel able to express their emotions. For example, the therapist may ask: "What emotions have you experienced since learning about your partner's online relationship? How has your partner reacted towards these emotions? Do you think that it is okay to be feeling this way about online behaviors?" Normalizing the range of emotions felt and providing space for the partner to express them in session will be an important aspect during this stage of treatment, especially if the participating partner believes online behaviors are not cheating. Additionally, the possibility that the Facebook infidelity may be known by all of the couple's Facebook friends may increase feelings of embarrassment, anger, and shame that might not have been so prominent if the incident was not publically displayed on Facebook. Therapeutic sessions can be dedicated to addressing concerns about the impact of the infidelity on their social support network and how to better manage what is posted on their social networking sites.

\section{FUTURE RESEARCH}

Future research in the area of Facebook infidelity will help this body of scholarship catch up to the existing scholarship on Internet infidelity and compulsive online sexual behaviors. Gaps in the existing literature include a need to: define Facebook infidelity, conduct studies that utilize both partners to gather couple level data, identify motivational factors, understand the differences between Facebook infidelity and other Internet behaviors, and learn how rules and boundaries are communicated in intimate partner relationships.

Although previous researchers have identified the difficulties inherent in setting one standard definition of offline and online infidelity, endeavors could explore what the general population considers to be Facebook infidelity. Definitions may come from exploring what behaviors individuals believe to be inappropriate or finding a general definition that focuses on the process (i.e., secrecy, breaking rules) instead of specific behaviors. These definitions can then move into understanding how couples establish rules and boundaries for Internet use, what factors help couples to be more likely to overtly establish rules for the Internet and how couples resolve disagreement in what behaviors should be off limits.

Finally, future research should be conducted to explore the differences and similarities between offline infidelity, Internet infidelity, online sexual compulsivity, and SNS infidelity in terms of the impact each form of infidelity has on the relationship and the individual partners. A comparative study of 
this nature would help researchers and clinicians not only understand the continuum of infidelity behaviors to a greater extent, but it would also aid in creating models for treatment that focus on specific factors associated with each infidelity type and which factors exist across the spectrum.

\section{REFERENCES}

Bergner, R. M., \& Bridges, A. J. (2002). The significance of heavy pornography involvement for romantic partners: Research and clinical implications. Journal of Sex \& Marital Therapy, 28(3), 193-206. doi:10.1080/00926232760328235

Bridges, A. J., Bergner, R. M., \& Hesson-McInnis, M. (2003) Romantic partners' use of pornography: Its significance for women. Journal of Sex \& Martial Therapy, 29, 1-14.

Cooper, A. (1998). The Internet and sexuality: Surfing into the new millennium. CyberPsychology \& Behavior, 1, 187-193. doi:10.1089/pb.1998.1.187

Cooper, A., \& Griffin-Shelley, E. (2002). Introduction. The Internet: The next sexual revolution. In A. Cooper (Ed.), Sex and the Internet: A guidebook for clinicians (pp. 5-29). New York, NY: Brunner-Routledge.

Cravens, J. D. (2013). Social networking infidelity: Understanding the impact and exploring rules and boundaries in intimate partner relationships (Doctoral dissertation). Lubbock: Texas Tech University.

Cravens, J. D., Leckie, K. R., \& Whiting, J. B. (2013). Facebook \& infidelity: When poking becomes problematic. Contemporary Family Therapy, 35, 74-90. doi:10.1007/s1059101209231-5

Cravens, J. D., \& Whiting, J. B. (2014). Facebook infidelity: A story completion method. Manuscript in preparation.

Daines, B. (2006). Violations of agreed and implicit sexual and emotional boundaries in couple relationships - some thoughts arising from Levine's 'A clinical perspective on couple infidelity.' Sexual and Relationship Therapy, 21, 45-53. doi:10.1080/14681990500430011

Glass, S. P., \& Wright, T. L. (1992). Justifications for extramarital relationships: The association between attitudes, behaviors, and gender. Journal of Sex Research, 29, 361-387. doi:10.1080/00224499209551654

Helsper, E. J., \& Whitty, M. T. (2010). Netiquette within married couples: Agreement about acceptable online behavior and surveillance between partners. Computers in Human Behavior, 26, 916-926. doi:10.1016/j.chb.2010.02.006

Henline, B. H., \& Lamke, L. K. (2003, November 19-22). The experience of sexual and emotional online infidelity. Poster presented at the 65th annual conference of the National Conference on Family Relations, Vancouver, Canada.

Henline, B. H., Lamke, L. K., \& Howard, M. D. (2007). Exploring perceptions of online infidelity. Personal Relationships, 14, 113-128.

Hertlein, K. M., \& Piercy, F. P. (2006). Internet infidelity: A critical review of the literature. The Family Journal: Counseling and Therapy for Couples and Families, 14, 366-371. doi:10.1177/1066480706290508 
Hertlein, K. M., \& Piercy, F. P. (2008). Therapists' assessment and treatment of Internet infidelity cases. Journal of Marital and Family Therapy, 34, 481-497.

Hertlein, K. M., \& Stevenson, A. (2010). The seven "As" contributing to Internetrelated intimacy problems. Cyberpsychology \& Behavior, 7, 207-230.

Johnson, R. E. (1972). Attitudes toward extramarital relationships. Medical Aspects of Human Sexuality, 6, 168-191.

Jones, K. E., \& Hertlein, K. M. (2012). Four key dimensions for distinguishing Internet infidelity from Internet and sex addiction: Concepts and clinical application. The American Journal of Family Therapy, 4O(2), 115-125. doi:10.1080/01926187.2011.600677

King, S. (1999). The impact of compulsive sexual behaviors on clergy marriages: Perspectives and concerns of the pastor's wife. Sexual Addiction E Compulsivity, 10, 193-199. doi:10.1080/107201603902306307

Kitzinger, C., \& Powell, D. (1995). Engendering infidelity: Essentialist and social constructionist readings of a story completion task. Feminism and Psychology, 5, 345-372.

Kraut, R., Patterson, M., Lundmark, S. K., Mukopadhyay, T., \& Scherlis, W. (1998). Internet paradox: A social technology that reduces social involvement and psychological well being? American Psychologist, 53, 1017-1031.

Leiblum, S. R., \& Döring, N. (2002). Internet sexuality: Known risks and fresh chances for women. In A. Cooper (Ed.), Sex and the Internet: A guidebook for clinicians (pp. 19-45). New York, NY: Brunner-Routledge.

Lumpkin, S. (2012, May 24). Can Facebook ruin your marriage? ABC World News. Retrieved from http://abcnews.go.com/Technology/facebookrelationshipstatus/ story?i=16406245\#.T8e02 9PE

Norton, A. M. (2011). Internet boundaries for social networking: Impact of trust and satisfaction (Master's thesis). Kansas State University, Manhattan, KS.

Roscoe, B., Cavanaugh, L. E., \& Kennedy, D. R. (1988). Dating infidelity: Behaviors, reasons, and consequences. Adolescence, 23, 35-43.

Schneider, J. P. (2000). A qualitative study of cybersex participants: Gender differences, recovery issues, and implications for therapists. Sexual Addiction $\mathcal{E}$ Compulsivity, 7, 249-278.

Smith, A., Segall, L., \& Cowley, S. (2012, October 4). Facebook reaches one billion users. CNNMoney. Retrieved from http://money.cnn.com/2012/10/04/ technology/facebookbillion-users/index.html

Thompson, A. P. (1983). Extramarital sex: A review of the research literature. Journal of Sex Research, 19, 1-22.

Whitty, M. T. (2003). Pushing the wrong buttons: Men's and women's attitudes toward online and offline infidelity. CyberPsychology and Behavior, 6, 569-579. doi: $10.1089 / 109493103322725342$

Whitty, M. T. (2005). The realness of cybercheating: Men's and women's representations of unfaithful Internet relationships. Social Science Computer Review, 23, 57-67. doi:10.1177/0894439304271536

Wilson, L. L., Roloff, M. E., \& Carey, C. M. (1998). Boundary rules: Factors that inhibit expressing concerns about another's romantic relationship. Communication Research, 25, 618-640. 
Yarab, P. E., Sensibaugh, C. C., \& Rice Allgeier, E. (1998). More than just sex: Gender differences in the incidence of self-defined unfaithful behavior in heterosexual dating relationships. Journal of Psychology \& Human Sexuality, 10, 45-57.

Young, K. (1998). Caught in the Net: How to recognize the signs of Internet addiction and achieving strategies for recovery. New York, NY: Wiley.

Zitzman, S. T., \& Butler, M. H. (2005). Attachment, addiction, and recovery: Conjoint marital therapy for recovery from a sexual addiction. Sexual Addiction $\&$ Compulsivity, 12, 311-337. 